\title{
Patterns of antenal sensilla of Panstrongylus megistus from three Brazilian states
}

\author{
MM Villela, S Catalá*, J Juberg**, IG Silva***, JCP Dias/+
}

\begin{abstract}
Centro de Pesquisas René Rachou-Fiocruz. Av. Augusto de Lima 1715, Belo Horizonte, MG, Brasil *Centro Regional de Investigación Científica y Transferencia Tecnológica de La Rioja, Anillaco, Argentina **Instituto Oswaldo Cruz-Fiocruz,

Rio de Janeiro, RJ, Brasil ***Departamento de Parasitologia, Universidade Federal de Goiás, Goiânia, GO, Brasil
\end{abstract}

The objective of the present study was to analyze and describe the phenotype of the antennal sensilla of Panstrongylus megistus, one of the epidemiologically most important species of triatomines in Brazil. Specimens from the Brazilian states of Goiás (GO), Minas Gerais (MG), and Rio Grande do Sul (RS) were compared, based on studies of four types of sensilla on three antennal segments: thick-walled trichoid (TK), thin-walled trichoid (TH), bristles (BR), and basiconica (BA). Discriminant analysis allowed the separation of the RS specimens from those of $G O$ and MG. Multivariate discriminant analysis demonstrated that the sensilla of males differed from those of females, the variables with greatest weight being the BA of all three segments and the TK of flagellum 1. The basiconica sensilla were significantly more abundant in females, on all three segments. Antennal sensilla patterns also demonstrated significant differences among P. megistus specimens.

Key words: Panstrongylus megistus - antennal sensilla - Chagas disease - Brazil

Triatomine bugs are haematophagous insects that transmit Trypanosoma cruzi, aetiological agent of Chagas disease (Schofield 1994). About 137 species are currently known, grouped into 19 genera and six tribes (Galvão et al. 2003). Most of these insects are silvatic and associated with a wide variety of habitats and vertebrate hosts, particularly in mammal and bird nests. Others occupy domestic and peridomiciliary habitats such as chicken houses and a few are completely adapted to the domestic environment, being important vectors of $T$. cruzi in this ecotope (Schofield et al. 1999). In Brazil, five species have major epidemiological importance in human Chagas disease (Dias \& Coura 1997): Triatoma infestans (Klug 1834), Panstrongylus megistus (Burmeister 1835), T. brasiliensis Neiva, 1911, T. sordida (Stal, 1859), and T. pseudomaculata Corrêa \& Espínola 1964.

$P$. megistus occurs in humid areas, particularly Atlantic forest, being present in all types of forest in Brazil outside the Amazon region, being dispersed chiefly from the coast forests ("Mata Atlântica") to western direction (Forattini 1980). In Northeast and Southeast regions, the species is frequently captured in human dwellings, also being found in natural biotopes (Freitas et al. 1960, Forattini et al. 1979). In the South, it is well known that $P$. megistus does not infest dwellings being detected in natural biotopes of preserved ecosystems on the Santa Catarina and Paraná coast (Luz 1976). Nevertheless, eventually, it can be captured in houses and outbuildings of particular areas submitted to high anthropic activities, as

Financial support: in party by TDR (UNDP, WB, WHO) ${ }^{+}$Corresponding author. E-mail: jcpdias@cpqrr.fiocruz.br Received 19 May 2005

Accepted 4 October 2005 it was observed particularly in Minas Gerais and Bahia states (Silva \& Silva 1990, Dias \& Coura 1997). Thus, in Brazil, P. megistus presents marked epidemiological differences from region to region.

The genetic and morphological changes shown by certain triatomine species have been described as adaptations of silvatic insects to the domestic environment (Dujardin et al. 1998). Many of these adaptations deal with the mechanisms the insects use to find sources of blood meals, $\mathrm{CO}_{2}$, heat, and odour being orientation stimuli used by the bugs to find their vertebrate hosts (Lazzari \& Nunes 1988, Lazzari 1990). Triatomines use mainly the antennae to detect these stimuli and many others related to sex, refuge, and habitat preferences (Wigglesworth \& Gillett 1934, Bernard 1974). The antennae are composed of four segments (scape, pedicel, and flagellum 1 and 2), each one with a wide variety of sensilla. The sensilla are cuticular structures associated with bipolar neurons on the epidermis and are the sensorial receptors that mediate the relationship between the insects and the environment, presenting several types of mechanoreceptors, chemoreceptors, and probably thermohygroreceptors (Gracco \& Catalá 2000). Studies have already been carried out on the antennal sensilla of several triatomine species (Catalá \& Schofield 1994, Catalá 1997a, b, Catalá \& Dujardin 2001). On the other hand, analysis of the antennal phenotype allowed geographical populations of $T$. dimidiata and $T$. infestans (Catalá 1997b, Catalá \& Dujardin 2001) to be separated. However, to date there have been no detailed studies of the antennal phenotype of $P$. megistus.

The objective of the present study was to analyse and describe the antennal phenotypes of $P$. megistus comparing their characteristics in specimens from three Brazilian states: Goiás (GO), Minas Gerais (MG), and Rio Grande do Sul (RS). In MG, P. megistus is frequently found in human dwellings, while in RS it is mainly silvatic. In GO, the species seems to be in transition, being found both in sylvatic and peridomestic ecotopes (Forattini el al. 1983). 
For this reason, we were interested in finding whether antennal phenotypes differed enough to permit separation of the specimens collected in three different Brazilian regions, and if such differences were reflected in their degrees of association with human habitations. Considering the relative low number of available insects, the present results must be considered basically preliminary. Even though, some significant findings emerged from the research and are related here, naturally requiring further investigation.

\section{MATERIALS AND METHODS}

Insect collections - All the specimens ( $20 \mathrm{~F} 1$ adults of $P$. megistus) descended from insects collected in peridomiciliary chicken houses of rural areas in the following localities: 8 (4 males and 4 females), from the Centro de Pesquisa René Rachou-Fiocruz (Belo Horizonte, MG), the parental generation having been collected in Bambuí, western MG; 8 ( 4 males and 4 females) from the Universidade Federal de Goiás (Goiânia, GO), the parental generation from Goiânia City (GO); and 4 females from the Instituto Oswaldo Cruz-Fiocruz (RJ), the parental generation from Montenegro County (midwestern region of RS).

Antennal analysis preparations - Analyses of the antennal sensilla have traditionally been based on their external appearance in bright field microscopy (Schenk 1903). One antenna of each specimen was removed at the level of the scape using forceps and diaphanised in $\mathrm{NaOH}$ $3 \%$ solution at $55^{\circ} \mathrm{C}$ for $4 \mathrm{~h}$, according to Gracco and Catalá (2000). After neutralization with acetic acid, each antenna was mounted in glycerine under a coverslip on a slide. The ventral surface of the antennae was examined by a light microscope using 400 magnification. For each specimen, the ventral side of the three distal segments of the antennae was drawn, identifying and counting the following receptors according to Catalá and Schofield (1994): bristles (BR), thin walled trichoid (TH), thick walled trichoid (TK), and basiconica (BA).

The mean numbers of each type of sensillum in both sexes were compared by means of the T-test. The data set was analysed using PADWIN version 60, to estimate functions that identify the studied groups. PADWIN (Dujardin 2004, http://www.mpl.ird.fr/morphometrics) is a software performing classical discriminant analyses, by estimating statistical significance (of Wilks value and of Mahalanobis distances values) in a non parametric way, by permutation tests. One thousand permutations were used to estimate statistical significances. The discriminant analysis was carried out with the variables that produced the high- est contribution to explain variability in the description of the studied specimens.

\section{RESULTS}

All four types of sensilla were present on both the pedicel and the flagellum segments, in all the specimens. Details are shown in Fig. 1.

Table I shows the mean number of sensilla in each segment, according to sex, as well as the mean numbers of BR,TH,TK, and BA on flagellum 1 and 2, and BR,TH, and BA on the pedicel. The number of TK on the pedicel was not counted, since their high number on this segment of the antenna could lead to methodological errors.

Univariate analysis did not demonstrate significant differences between the sexes for any of the variables. However, tendencies towards a greater number of $\mathrm{TH}$ on the pedicel of the males and an increase in BA of the three segments and TK on the flagellum 1 of the females were observed (Table I). When both sexes were subjected to

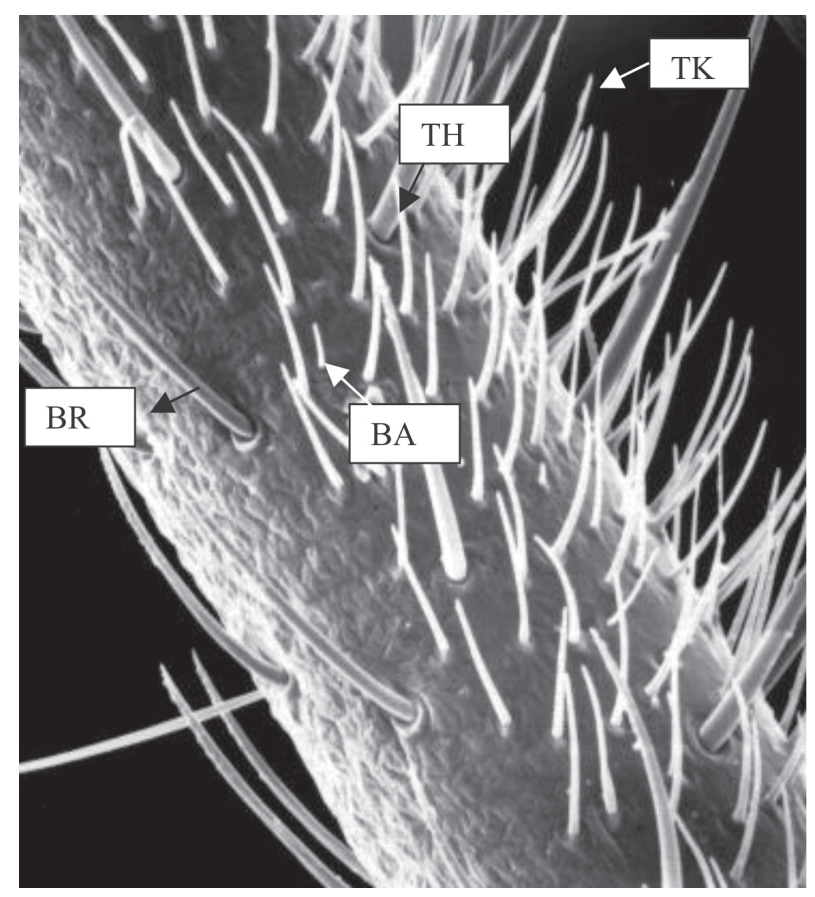

Fig. 1: antennal pedicel of Panstrongylus megistus increased 200× (scanning electron microscopy picture by $\mathrm{S}$ Catalá). The chimioreceptors thin walled trichoid $(\mathrm{TH})$, thick walled trichoid (TK), and basiconica (BA) are concentrated in the ventral region (right). Mecanoreceptors bristles (BR) can be seen homogeneously distributed over all the surface.

TABLE I

Average of antennal sensilla found by segment, and in accordance with the sex

\begin{tabular}{|c|c|c|c|c|c|c|c|c|c|c|c|c|}
\hline \multirow[t]{2}{*}{ Sex } & \multicolumn{3}{|c|}{ Pedicel $^{a}$} & \multicolumn{3}{|c|}{ Flagellum 1} & & \multicolumn{4}{|c|}{ Flagellum 2} & \multirow[t]{2}{*}{ Total } \\
\hline & $\mathrm{BR}$ & $\mathrm{TH}$ & $\mathrm{BA}$ & BR & $\mathrm{TH}$ & TK & BA & BR & $\mathrm{TH}$ & TK & BA & \\
\hline Female & 40,6 & 199 & 11,3 & 23,3 & 78,3 & 159 & 35,8 & 10,2 & 28,3 & 132,2 & 19,8 & 737,8 \\
\hline Male & 39,8 & 235,8 & 3,8 & 15,6 & 78,6 & 130,4 & 10,8 & 10,2 & 19,1 & 138,3 & 12,6 & 695 \\
\hline
\end{tabular}

$a$ : in pedicel the TK was not entered; BR: bristles; TH: thin walled trichoid; TK: thick walled trichoid; BA: basiconica 
multivariate discriminant analysis, males differed significantly from the females, the variables with greatest weight being the BA sensilla of the three segments and the TK of flagellum 1.

Discriminant analysis of the different origins allowed the RS specimens to be separated from those of GO and MG (Wilks 0.124; F: 6.44; $\mathrm{p}=0.0001$ ). Localizations of individuals on the axes of the first two canonic functions are shown in Fig. 2. Note that the RS specimens are distinct from those of GO and MG but the latter two cannot be completely separated from each other.

The mean number of sensilla of each antennal segment of the specimens from RS, GO, and MG is shown in Table II. Note that the number of TK on both flagellum segments was higher in the MG specimens.

\section{DISCUSSION}

Given the epidemiological importance of $P$. megistus in Brazil and the different types of behaviour shown by this species, new tools for analysing the morphology of these insects are important, since they could help elucidate the different bio-ecological characteristics presented by the insect. Univariate analysis of the sensilla of males and females of $P$. megistus did not demonstrate signifi- cant differences between the sexes for any variable. However when discriminant multivariate analysis was carried out for both sexes, significant differences were observed between females and males, BA sensilla being significantly more abundant in the females, in all three segments. This type of sensillum is very porous and permits the insects to perceive particles liberated by the sweat and respiration of the hosts, as well as pheromones (Bernard 1974). The greater density of this sensillum in females is probably explained by the role it plays in host finding, as observed for other species (Chaika 1980, Guerenstein \& Guerin 2001). The greater abundance of BA in the females may also be related to more efficient host-seeking behaviour, since females in particular need to ingest more blood to produce eggs and undertake long migratory flights after mating (Dias \& Dias 1968, Forattini et al. 1983, Montenegro \& Pasina 1984). By contrast the TK sensillum presents only one pore at the apex and its function is unknown. The TH of the pedicel are more abundant in the males, as in T. sordida (Catalá 1997 b).

In T. dimidiata and T. infestans (Catalá \& Dujardin 2001) one type of trichoid sensillum (TK) was found in greater numbers on the antennae of bugs from domestic populations than on those from insects captured in silvatic

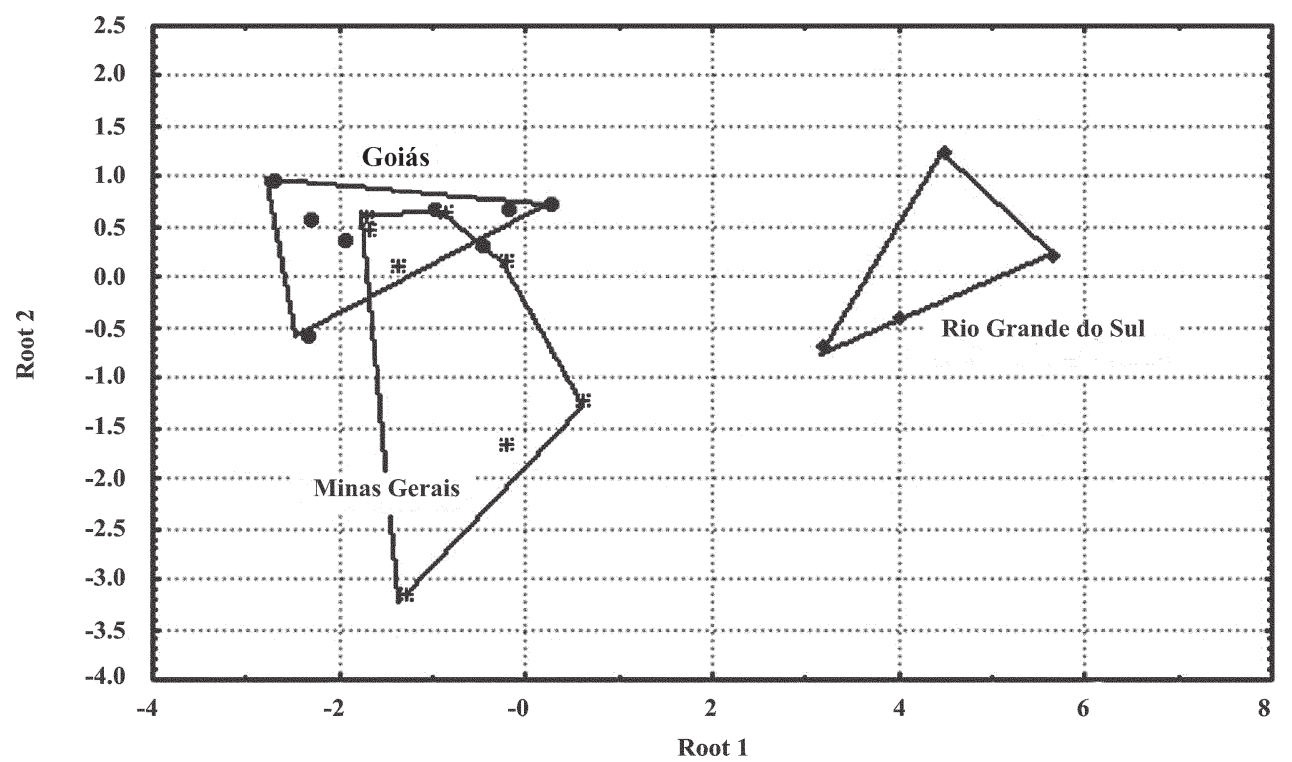

Fig. 2: discriminant analysis for Panstrongylus megistus specimens from Minas Gerais, Goiás, and Rio Grande do Sul, using four variables: bristle of pedicel, thick walled trichoid of flagellum 1, basiconica, and thick walled trichoid of flagellum 2 . Each point represents a specimen of $P$. megistus. Root 1 and root 2 are the two first canonical functions.

TABLE II

Averages numbers of the antennal sensilla on each segment, in accordance with the origin (Brazilian states) of Panstrongylus megistus

\begin{tabular}{|c|c|c|c|c|c|c|c|c|c|c|c|}
\hline \multirow[t]{2}{*}{ Origin (states) } & \multicolumn{3}{|c|}{ Pedicel } & \multicolumn{4}{|c|}{ Flagellum 1} & \multicolumn{4}{|c|}{ Flagellum 2} \\
\hline & $\mathrm{BR}$ & TH & $\mathrm{BA}$ & $\mathrm{BR}$ & $\mathrm{TH}$ & TK & $\mathrm{BA}$ & $\mathrm{BR}$ & $\mathrm{TH}$ & TK & BA \\
\hline Goiás & 37,4 & 201,6 & 6,8 & 19,9 & 76,1 & 132 & 19,6 & 8,5 & 24,5 & 133,8 & 12,5 \\
\hline Rio Grande do Sul & 44,8 & 219,6 & 10,4 & 23,6 & 62,2 & 132,2 & 27,8 & 7,8 & 21 & 126,6 & 21,8 \\
\hline Minas Gerais & 40,3 & 223,6 & 7,9 & 17,6 & 86,4 & 171,5 & 28,9 & 12,5 & 24 & 141 & 17,9 \\
\hline
\end{tabular}

BR: bristles; TH: thin walled trichoid; TK: thick walled trichoid; BA: basiconica 
environments and was therefore proposed as a domiciliation marker. In the present study, P. megistus specimens from MG showed more TK on flagellum 1, a result consistent with the historical data on Chagas disease for this state, which has one of the highest indices of household capture of this species in Brazil (Villela et al. 2005). According to Forattini (1980) P. megistus specimens captured in MG present distinct behaviour to those of RS. While this species often invades houses and the peridomicile in MG, it occurs almost exclusively in silvatic environments in RS. However we did not find higher numbers of TK on the antennae of P. megistus captured in GO, possibly reflecting the lower degree of domiciliation in this state.

The patterns of antennal sensilla revealed differences among P. megistus specimens in the present study. Comparisons with specimens from other sites would provide valuable information, as would the inclusion of a greater number of specimens in the observation. Furthermore, comparisons among different habitats within the same region would permit the role of the antennal phenotype to be established in relation to the type of habitat colonized by a species.

\section{REFERENCES}

Bernard J 1974. Étude Electrophysiologique des Récepteurs Impliqués dans l'Orientation vers l'Hôte et dans l'Acte Hematophage chez un Hemiptère Triatoma infestans, Thesis, Université de Rennes, Rennes, France, 265 pp.

Catalá S 1997a. Antennae and rostrum. RU Carcavallo, GL, Girón, J Juberg, H Lent (eds), Atlas dos Vetores da Doença de Chagas nas Américas, Fiocruz, Rio de Janeiro, p. 74-84.

Catalá S 1997b. Antennal sensilla of triatominae (Hemiptera, Reduviidae): a comparative study of five genera. Int J Insect Morphol \& Embryol 26: 67-73.

Catalá S, Dujardin JP 2001. Antennal sensilla patterns indicate geographic and ecotopic variability amog Triatoma infestans Hemiptera:Reduviidae populations. J Med Entomol 38: 423428.

Catalá S, Schofield CJ 1994. The antennal sensilla of Rhodnius. J Morphol 21: 193-203.

Chaika S 1980. Ultrastructure of the antennal sensilla of the bug, Rhodnius prolixus (Hemiptera, Reduviidae). Parazitologiia 14: 486-492.

Dias E, Dias JCP 1968. Variações mensais da incidência de formas evolutivas do Triatoma infestans e do Panstrongylus megistus no município de Bambuí, MG. Mem Inst Oswaldo Cruz 66: 209-226.

Dias JCP, Coura JR 1997. Epidemiologia. In JCP Dias, JR Coura (eds), Clínica e Terapêutica da Doença de Chagas. Uma Abordagem Prática para o Clínico Geral, Fiocruz, Rio de Janeiro, p. 33-67.

Dujardin JP, Forgues G, Torrez M, Martinez E, Córdoba C, Gianella A 1998. Morphometrics of domestic Panstrongylus rufotuberculatus in Bolívia. Ann Trop Med Parasitol 92: 219-228.

Forattini OP 1980. Biogeografia, origem e distribuição da domiciliação de triatomíneos no Brasil. Rev Saúde Púb 14: 265-299.
Forattini OP, Ferreira OA, Rabello EX, Barata JMS, Santos JLF 1983. Aspectos ecológicos da tripanossomíase americana. XIX - Desenvolvimento da domiciliação triatominea regional, em centro de endemismo de Panstrongylus megistus. Rev Saúde Púb São Paulo 17: 436-460.

Forattini OP, Ferreira OA, Rocha e Silva EO, Rabello EX 1979. Aspectos ecológicos da tripanossomíase americana. XIV. Persistência e potencial de domiciliação de populações triatomínicas silvestres em região de intensa atividade agropecuárea. Rev Saúde Púb 13: 123-146.

Freitas JLP, Siqueira AF, Ferreira OA 1960. Investigações epidemiológicas sobre triatomíneos de hábitos domésticos e silvestres com auxílio da reação de precipitina. Rev Inst Med Trop São Paulo 2: 90-99.

Galvão C, Carvalho RU, Rocha DS, Juberg J 2003. A check-list of the current valid species of the subfamily Triatominae Jeannel, 1919 (Hemiptera, Reduviidae) and their geographical distribuition, with nomenclatural and taxonomix notes. Zootaxa 202:1-36.

Gracco M, Catalá S 2000. Inter-specific and developmental difference on the array of antennal chemoreceptors in four species of triatominae (Hemiptera:Reduviidae). Mem Inst Oswaldo Cruz 95: 67-74.

Guerenstein PG, Guerin PM 2001 Olfactory and behavioural responses of the blood-sucking bug Triatoma infestans to odours of vertebrate hosts. Exp Biol 204: 585-97.

Lazzari CR 1990. Fisiologia del Comportamiento de Triatoma infestans (Klug, 1834) (Heteroptera: Reduviidae). Orientación Térmica, PhD Thesis, Universidad de Buenos Aires, Buenos Aires, 375 pp.

Lazzari CR, Núñez J 1988. Blood temperature and feeding behaviour in Triatoma infestans (Heteroptera: Reduviidae). Entomol Gener 14: 183-188.

Luz E 1976. Focos silvestres do Trypanosoma cruzi no litoral e primeiro planalto paranaense. An Med Univ Fed Paraná 19: 7-51

Montenegro S, Pasina L 1984. Consumo y utilización del alimento en adultos de Triatoma infestans (Klug, 1834). Physis 42: 127133.

Schenk O 1903. Die antennalen hautsinnesorgane einiger Lepidopteren und Hymenopteren. Zool Jb Anat 17: 573618.

Schofield CJ 1994. Triatominae: Biología y Control, Eurocommunica Publications, United Kingdom, 80 pp.

Schofield CJ, Diotaiuti L, Dujardin JP 1999. The process of domestication in Triatominae. Mem Inst Oswaldo Cruz 94 (Suppl. I): 375-378.

Silva IG, Silva HHG 1990. Ocorrência de Panstrongylus megistus (Burmeister, 1835) colonizando habitação em Goiânia. Rev Patol Trop 19: 163-165.

Villela MM, Souza JB, Mello VP, Azevedo BVM, Dias JCP 2005. Vigilância entomológica da doença de Chagas na região centro-oeste de Minas Gerais, Brasil, entre os anos de 2000 e 2003. Cad Saúde Públ 21: 878-886.

Wigglesworth VB, Gillett JD 1934. The function of the antennae in Rhodnius prolixus (Hemiptera) and the mechanism of orientation to the host. J Exp Biol 11: 120-139. 